uterus was found normal in size and anteverted. Behind it was an obscure swelling extending into the abdomen as far as the umbilicus. Menstruation was now regular, and had been for the last four months. The pain was better, the sensation of bearing-down almost gone, and the general health much improved. Soon after this things changed for the worse; the pain increased, and the patient's health began seriously to suffer. On Sept. 22nd the retro-uterine swelling had increased, and gave evidence of fluctuation there was distinct bulging of the vaginal roof in the right lateral fornix; the abdominal swelling was more prominent and exceedingly tender, but nowhere absolutely dull on percussion. The patient had now become absolutely incapable of the least exertion. There being no improvement after three weeks' absolute rest, I determined to make an exploratory incision. This was done on Oct. 12th, 1887. At the posterior part of the pelvis on the right side there was found, walled in by adherent viscera, a large abscess, from which twenty ounces of yellowish-green pus were evacuated. The abscess carity extended downwards into Douglas's pouch, and upwards to a distance of two inches above the level of the umbilicus. The inner surface of the wall of the abscess was at the upper part rough and irregular; smooth below. The whole abscess was deeply seated, the abdominal viscera, matted together by adhesions, lying between it and the anterior abdominal wall. With great difficulty the very friable tissues at the margin of the opening were stitched to the edges of the abdominal incision, the upper part of the abdominal incision being closed by sutures. A glass drainage tube was passed into the abscess cavity. On the fourth day an indiarubber drainare tube was substituted for the glass one. The abscess cavity contracted very slowly, pus continuing to be discharged freely for several months. On March 10tl, 1888, the tube was removed, and the patient was allowed to go home. Pus was still issuing freely from the sinus, which had not closed when I last heard of the patient. I very much regret that I did not operate sooner in this case, instead of waiting for definite signs of suppuration.

The last case (No. 9) of the series was a married woman (Mrs. D-) aged fifty-two, in whom an exploratory incision was made, at her own home near Manchester, on March 9th, 1888, on account of a very large, irregular, solid abdominal tumour, accomnanied with ascites and cedema of the lower extremities. The swelling was first noticed about Christmas, 1887 , and had grown with great rapidity. The patient was a stout, heavy woman, with pale flabby tissues and weak circulation. The operation was undertaken almost as a forlorn hope. The abdominal cavity was found to be filled with cancerous growth, which it was impossible to remove. An enormous quantity of ascitic fluid was allowed to drain away, and the incision was then closed. The patient quickly sank, and died twelve hours after the operation. Under any circumstances she could not have survived many days.

The mortality in this short series of cases was excessively high, but it must be allowed that the proportion of desperate cases was altogether unusual. Of the five patients who died, three were the victims of malignant disease. Had I been solicitous for favourable statistics, I should in each of these cases have declined to operate. It is not, however, in my opinion, the duty of an operator to select his cases with a view to enhancing his own reputation, but to take that course which in each case appears to him the best for his patient.

Brook-street, W.

\section{A CASE IN WHICH THE GLADIOLUS WAS TREPHINED FOR PUS PENT UP IN THE ANTERIOR MEDIASTINUM.'}

By CHARLES A. BALLANCE, M.S., F.R.C.S.,

SENIOR ASSLSTANT SURGEON, WEST LONDON HOSPITAL; ASSISTANT SURGEON FOR EAR DISEASES, S'T. THOMAS'S HOSPITAL.

Mrs. X-aged thirty-five years, tall, fairly well nourished, and of energetic habits, was a patient of my friend Dr. Jardine of Richmond. She was admitted to 'St. Thomas's Home for surgical treatment. I saw her first on August 31st, 1887. She complained of a discharging abscess over the front of the upper part of the chest,

1 Read before the Medical Society, October 15th, 1888. accompanied hy constant and severe pain and great tenderness along the breast bone; also of fever, anorexia, general malaise, loss of strength, and want of sleep. The notes of August 3lst are as follows: "Two years ago (after the birth of the last child) she had a severe illness, and was in bed for more than three months suffering, she says, from 'inflammation of the lungs.' Since that time she has never been quite well. Three months ago, after she had experienced for many weeks a good deal of pain in the middle of the chest, a lump about two inches in diameter formed over the upper part and left side of the sternum. This was treated in various ways, but the skin becomino involved, an incision was made by Dr. Jardine, and much pus evacuated. Since this time-that is, since two month ago-a sinus has formed, through which pus daily escapes in variable quantities. During the last three or four months she has suffered more or less continuously with fever, which she described as 'Mauritius fever,' having had much experience of a like character in that island in former years. She has had several children and no miscarriages. The family history is good. There is no tubercular taint, and with the exception of the illness here described, that following the last confinement and the "Mauritius fever,' she has always enjoyed good health. The pulse is 100 ; temperature $100^{\circ}$; tonoue slightly furred. The skin over the front of the sternum and for about eight inches beyond its left border is rel, odematous, and apparently undermined. A sinus, whose external opening corresponds to the site of the incision which had been made two months before, leads down to the left second costosternal articulation, where bare bone can be felt, and the probe, when appropriately bent, can be passed still further into a space behind the gladiolns. The sternum itself is acutely tender to palpation, and is the seat of a constant dull aching pain. Pain is caused by a deep inspiration or any movement of the shoulders and arms or abdomen which involves a muscular strain on the sternum. Three or four days agro another swelling was notieed to be forming over the left fourth, fifth, and sixth costal cartilages. This has betn gradually increasing in size, and all the tissues around are inflamed, red, and 'boggy.' For several days the discharge from the old sinus above has been less copious than usual. No other abnormal signs are present except some doubtful friction, pleural or pericardial, over the middle line in front. Hot fomentations locally and quinine internally were ordered.

Two days later, the general and local state not haring improved, the patient was placed under ether, the sinus freely opened up, and the lower "boggy" swelling incised. The probe then travelled easily between the left fourth and fifth cartilages, close by the left border of the gladiolus, into the anterior mediastinum, as it did when passed through the upper sinus. Chlorinated soda poultices were now applied, and the prone position enforced as much as pos sible; it was hoped that in this way a free discharge of pus would be encourged.

During the next three days no marlzed change occurred. The amount of pus which escaped was certainly not large but the ponltices gave a good deal of relief and local comfort.

Sept. 6th.-More pain. Less pus. Had a slight shiver in the afternoon. Temperature $102 \cdot 4^{\circ}$. Feels very ill and weak. Complete anorexia. Larger doses of quinine ordered. $104^{\circ}$

8th. - Since last note the temperature has not been below $102^{\circ}$, and this evening a rigor occurred in which the thermometer registered $103^{\circ}$. Sinuses almost dry. CEdema and boggy swelling increasing over front of chest. Dr. Hobhouse examined the chest, and found râles generally over the lungs, and friction sounds in front over their anterior borders. Sternum exquisitely tender. No percussion pos sible. Some pain complained of about left shoulder joint.

9th.-Another rigor. Temperature $103^{\circ}$. Pain and stiffness of left shoulder increased. No appreciable swelling of joint. Lung signs as before. Patient seems very ill.

10th. - Another rigor this afternoon. Temperature $104^{\circ}$. Mr. Pitts, who saw the case to-day, agreed with me that the mediastinum must be explored for pus, which was apparently there pent up.

11th. - Temperature $101^{\circ}$. The patient having been placed under the influence of ether, the two wounds were connected by a curved incision, the convexity of which was towards the right, so that the centre of the sternum was 
exposed. A transverse cut was afterwarls male to give more room. The erlarliolus having boen eleared of the superficial tissues, the periostemu was raised from the median line and pushed ontwards on each side by an elevator. There was as yet no sion of disease; the anterior surface of the bone secmed quite liealthy. A trephine (a little less than five-eighthe of an inch in diameter, which would make an opening through which my finger would easily pass) was then placed over the upper jart of the gladiolus a little to the left of the median line. After it had passed throurle the onter layer of compact tissue it soon became evident that the cancellous tissue beneath was carious. The circle of bone removed was very thick (more than a quarter of an inch), and permeated with pus; its inner surface was eroded. It was then determined to remove another circle of bone lower down (see diagram), and to cut away the portion of bone intervening between the two openings made by the trephine, so as to obtain anple room for exploration. The bridge of bone between the first trephine hole and the second left costo-sternal articulation, into which the probe had been previously passed, and which was diseased, was also cut through by the forceps and taken away. On looking

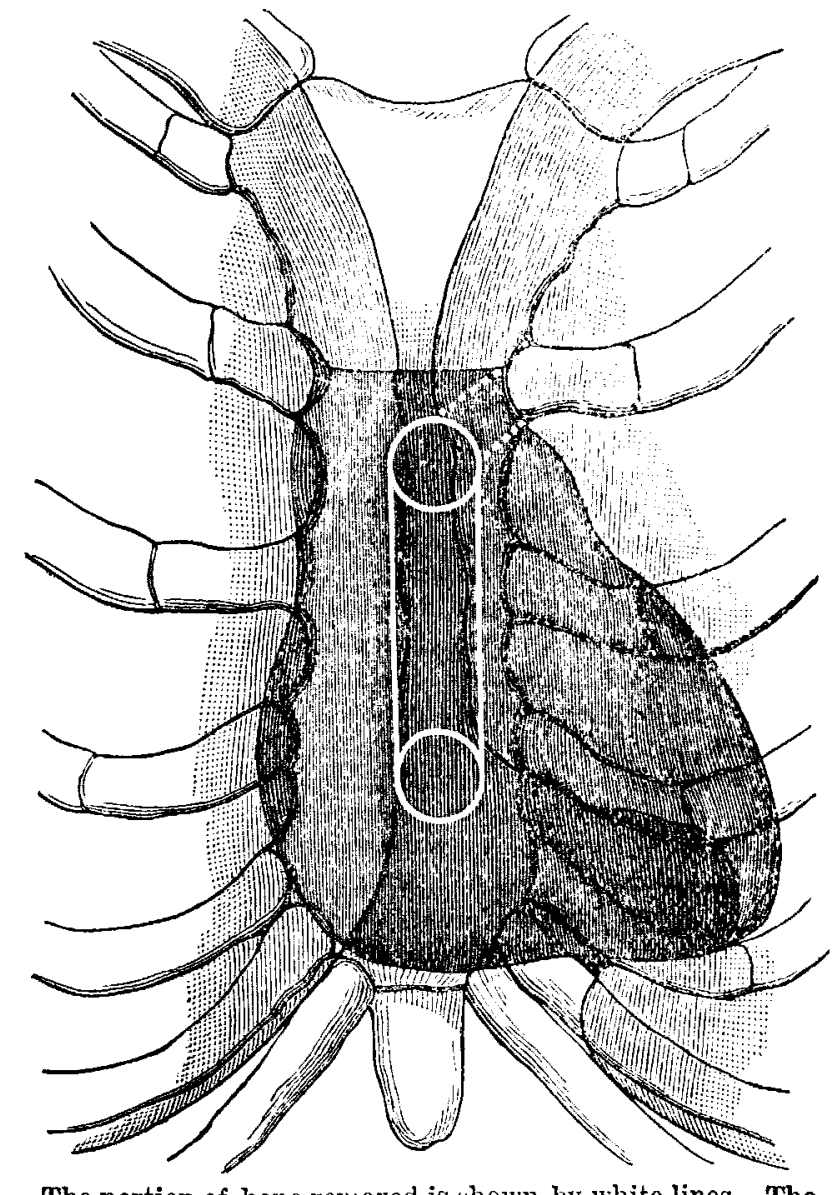

The portion of bone renoved is shown by white lines. The normal position of the lungs and pericirdium is indicated. (Half natural size.)

now into the anterior mediastium, a layer of thick creamy pus was seen on the front of the pericardium, and, on passing the probethrough the lower sinus, it was seen to emerge above much of the pus, which was collected in lar.sest quantity below the level of the inferior trephine aperture, and which had no doubt gravitated downwards as far as the lower limit of the inter-pleural space. The ju rulent collection was carefully syringed and wiped away. On exploring with the finger the posterior surface of the sternum the entire posterior aspect of the gladiolus was found to be carious. A Volkmann's spoon was then bent to the required angle and introduced into the mediastium, and the whole of the carious tissue removed, the spoon being guarded by a finger from injuring the plewre or other important structures. This took some time, and a by no means small quantity of carious material was brounht away. The left second costosternal articulation was also scraped. When no more soft or diseased bone could be scraped away, the cavity was irrigated with sublimate solution ( 1 in 1000 ) at $100^{\circ}$ for some time. Sublimate wet dressings ( 1 in 1000 ) were then gently packed in through the stermal opening to fill the mediastinal space, whilst a dry dressing of the same character was applied externally.
I need not give the details of the convalescence. The patient made a rapid and complete recovery. By the end of Jecember sho had regained her strength and the large wound had completely healed. The temperature never rose above normal. In forty-eight hours no râles in the lungs and no friction sounds in front were audible. The opening in the sternum seemed gradually to be filled in by fibrous tissue. The local treatment consisted in sublimate irrigation ( 1 in 1000 ) twice a day until the fluid could no longer gain access to the mediastinum. The dressing was wet (l in 1000) sublimate gauze until nothing could be passed beyond the sternum. Care was always used to wet only that portion of the gauze which passed within the chest, so as to avoid any irritation of the surrounding slin. Occasionally the dressings caused pain (for which fact I can offer no explanation), when they were changed to carbolic, eucalyptus, or iodoform for a day or two; but the daily morning and evening sublimate irrigation was never sus pended. The healing process was practically completed without simppuration.

This lady is now in the WVest Indies. I heard of her the other day-that is, about thirteen months after the operation,-and she is quite well.

Remarlis.-Though caries, gummatolis periostitis, and necrosis not rarely attack the sternum, I do not know of any case exactly like the above, or one in which such radical treatment has lueen applied to the posterior surface of the glarliolus. I took it from the first that the illness of the patient two years before I saw her had been puerperal or septic in origin, and had left some focus of disease in the inter-pleural space. Caries of the posterior surface of the gladiolus seemed to be the most likely cause of her condition; but the fact was not lost sight of that it might be due to breaking down of lymphatic glands, or possibly some still more obscure affection. The history of Mauritius fever increased the difficulty of diagnosis. The indications of pus retention were, however, pretty plain, and the critical state bordering on pyremia to which she was reduced necessitated prompt and active measures for her safety. At the operation, on examining the lateral or pleural boundaries of the anterior mediastinum, they appeared to be thickened and pushed away from the median line, leaving the whole posterior surface of the gladiolus exposed. The thickening of the pleura was no doubt due to the fact that the membrane had formed for three months part of the wall of the alscess cavity ; and it had an important bearing on the risk involved in injuring the membrane during the operation which I carried out. By scraping the posterior surface of the gladiolus I could not hope to eradicate all the germs of the disease; and the completely successful issue of the case was, I think, in no small degree due to the constant association of the diseased surfaces during convalescence with corrosive sublimate. The sternum has been trephined for abscess or foreign body in the mediastinum, for paracentesis pericardii, and the operation has been suggested in order to facilitate the ligation of the innominate. The two prominent symptoms of mediastina suppuration appear to be drspnca and constant severe pain. Mr. Hilton ${ }^{1}$ published a case in 1863 of sternal caries in a medical man, in which for many months the diagnosis was uncertain, but in which the above symptoms were present. Mr. Marshall, ${ }^{2}$ in a lecture delivered at the Brompton Hospital for Consumption in 1882, pointed out the difficulties surrounding the correct diagnosis of some cases of mediastinal alscess, in which an intercostal buloino devoid of all signs of inflamnation has an impulse on coughing, or an apparently expansile pulsation communicated from the heart. Dr. Eustace Smith 3 published in 1884 the case of a child who died from suppuration of the nediastinal glands in the East London Hospital for Children. The pus pointed at the second left interspace and at the episternal notch. The disease was tubercular. A merliastinal abscess has been said to have been discharged through the foramen sternale, ${ }^{4}$ an opening in the lower part of the gladiolus, which is occasionally present as a developmental defect. Many of the cases of nediastinal abscess, whether acute 01 chronic, ant whether associated with sternal caries or not, have a distinct history of traumatism. Dr. Goodhart ${ }^{5}$ in 1876 showed at the Pathological Society a specimen of diffuse mediastinal inflammation. The disease had proved

1 THE LANCET, vol. i. 1863. 3 Medical Times, vol. ii. 1884

4 'Treves' Surcical Applied Anatomy chapter on Thorax.

5 Path. Soc. 'Trans., vol. Xxviii.; and THE LANCET, vol. ii, 1876. 
rapidly fatal, and had commenced a few days after the man had received a severe blow on the sternum. Dr. Goodhart quotes from Dr. Pye-Snith, who collected fourteen cases of mediastinal suppuration from the post-mortem records of Guy's Hospital. No fewer than seven of these were acute cases. Mr. Walker ${ }^{6}$ read before the Sheffield MedicoChirurgical Society in 1884 a case of nediastinal abscess, with pleurisy, following a blow on the sternum ; and the late Sir W. Ferguson ${ }^{7}$ reported in 1858 a case of caries with abscess, due to the impact of a cricket ball, which he successfully treated by gouging away the disease. Perhaps the most remarkable case of meliastinal suppuration on record is described by Dr. Cooper. ${ }^{8}$ A gun exploded, and a large piece of iron lodged in the mediastinum of a man and set up extensive suppuration. As a last hope, an operation was performed, sufficient bone being removed to allow of a free exploration. A large quantity of pus was eracuated. The piece of iron was discovered resting against the descending aorta, behind the heart, and was extracted with the greatest difficulty by forceps!! The patient mace an excellent recovery. Dr. Marks of Milwaukee describes a case in which he made two trephine holes throngh the lower part of the gladiolus in order to remove a bullet from the anterior mediastinum of a man. It had lain the re for a long time, producing constant suppuration. Its situ ation liad not been determined, in spite of many examinations by different surgeons, until Dr. Marks passed along a sinus leading into the chest the stem of an ordinary clay pipe, which on withdrawal showed unmistakable signs of the presence of lead. The patient after the extraction of the bullet quickly convalesced. In con clusion, I may remark that it appears that those cases of mediastinal abscess which have been operated upon-or in other words, freely drained - have recovered; whilst those in which no operation has been done-or in other words, those in which the pus has been unable to escape-have died. This statement clearly defines the danger of allowing pus to be pent up in this region as elsewhere, emphasises the need for and the success attending prompt surgical interference, and claims the mediastinum as fit ground for the exercise of the surgeon's art.

Harley-street, W.

\section{CASE OF SYMMETRICAL GANGRENE (RAYNAUD'S DISEASE).}

BY JOHN J. WE A V E R. HOCSE SURGEON, SOUTHPORT INFIRMARY; IATE HOUSE SURGEON,

THE following case has been kept under observation for orer sixteen months. I am indebted to Dr. Fort of Oldham for permission to make notes of the case while the woman was under his care as a private patient, and although, at my request and with Dr. Fort's permission, she came on several occasions to the Oldham Infirmary, she was at no time an infirmary patient. The case presents some symptoms which, I believe, have not previously been recorded in connexion with this disease.

D. H-, aged forty-five, has been a widow for the last ten years, and is now living with her daughter. Her occupation consists in doing the housework at her daughter's and occasionally a little washing. Has always had good health, having had no previous illnesses beyond slight colds. There is no history of rheumatism, syphilis, chilblains, or grout, and she has not been exposed to malaria. She has always lived either in Manchester or Oldhan. The patient states that she has been in pretty easy circumstances, and has never had to work very hard. She could always get plenty of fool. As to alcohol, she says that she has been drinking warm porter lately; previously she took a little whisky now and then. I liad no reason, however, to think she was in any way given to excess. she has not been exposed to wet or cold, and there is nothing injurious in her dwelling or surroundings. The woman is the eldest of thirteen children; six sisters and one brother are living and healthy; the others she knows

G THE LANCET, vol. i. 1884 .

Trans 7 Ibil, vol. i. 1858.

Ranking's Abstracts, vol. i. 1858.

American Medical Record, June, 1E83; and Medical Recori, 18E4.

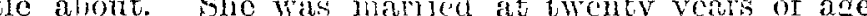
Her hushand died, ared fifty-fire, from "bronchitis" (two winters). She has had six children, the last two being twins; four are living and healthy. The twins died, one from "tecthing" when fourteen wecks old, and the other from scarlet fever when two years old. No miscarriages. No history of similar or any related (nervous or vascular) discase in family. The patient's father died, ased fortytwo, from "ulcerated throat" (had a silver tulse in the throat); her mother died, aged forty-nime, from " natural causes" "asthmatical and had cough"). The patient says that she had been feeling poorly for three or four weeks her appetite failed, and her fingers at times would feel stiff. On New Year's Day (Saturiay, Jan. 1 t.t, 1887) she went out to shake carpets, and found that her hancis became stiff she could move the fingers, but conid not hold anything. On the following day (Sunday) she got up early in the morning, and began washing the children (her daughter's) in warm water, and soon her fingers hegan to feel stiff, and, in addition, now became very painful (the first feeling of pain in them), so that she "liad to give la doing any thing." The whole length of the fingers and the ends of the thumbs were painful. The pain was described as "like after snow-balling," and the fingers were blue-looking and cold. She warmed her hands and put her fincers into mustardand-water; the pain was then "drealful." The same night (Sunday) she could not sleep on accomit of the pain; the fingers, as soon as they were made warm by putting them arrainst the body, became exceedingly painful, as though someone was "sawing them off"" The pain genorally commenced in the right hand, but in a few minutes afterwards would follow in the left hand. She always knew that when it had commenced in one hand it would soon begin in the other. While the pain lasted she was always very thirsty, and would drink a pint of tea in a short time. On the second night she drank freely of port wine, "about a gill," with quinine in it. She volunteered the statement that, though she drank freely of this, it did not make her sleep or feel intoxicated. This state of things lasted on and off for three weeks, there being also two or three attacks of pain during the day, but the worst at night. The patient always prepared something to drink when the rain came on; a small wineglassful at a time would quench the thirst. She called in Dr. Fort on Tuesday (Jan. 4th). The hands were rubbed during the first week, and medicine taken. During the second week the hands were wrapped in cotton wool and dry mustard, and linseed-meal poultices were applied during the third week. The patient states that the poultices then gave most relief. Abont a week after the first application of the poultices, the fingers in their whole length, from the metacarpo-phalangeal joints downwards, swelled up "like lladders." The patient thought the doctor would have pricked them when he came. They remained swollen about twelre hours, and then the swelling went down as suddenly as it had come on, and the skin then appeared to dry up. The skin on the palmar surface of the fingers and thmmls, from the metacarpophalangeal joints down to the last inter-phalangeal joints, then began to peel, and the ends of the fingers below the peeling began to turn black, but did not peel. 'The skin on the dorsal surface of the fincers and thmmbs was rough, but did not peel. There was pain in the thumbs at the same time as in the fingers, but it was not so great as in the fingers, nor did they turn black. If the thumbs, however, were left out of the poultices they beran to ache very much. About this same time, as the hands hegan to get a little easier, a "jumping pain " commenced on the plantar surface of the patient's heels, and when she put her feet near the fire the bic toes of both feet smarted and "lurehed" (just as the fingers had done) at their ends. There was no pain in the smaller toes. She put her feet in mustard-andwater, and also rubbed the heels with dry mustard; the heels hurt "like pins-and-needles" when she walked. The pain in the feet lasted abont a week.

Present state (March 5th, 1887).-.The natient is a thin woman of blue-looking coniplexion, as though cold. Nose blue, and some acne on nose and face. She states that she has never been very stont, but thinks herself thinner the last six weeks than she has ever been before. During the last winter she has not felt so well as formerly. hight hand: There is a dry, black slonoh on the jutyar surface of the first finger, extending above the last inter-yhalangeal joint; on the clorsal surface of the same finger a brown discolumation extends a litule above the nail. "rise skin is 